\title{
ANALISA FAKTOR FASILITAS MENJADI PENYEBAB TERLAMBATNYA PENGIRIMAN BARANG DALAM KEGIATAN DELIVERY DI GUDANG I PT. BHANDA GHARA REKSA
}

\author{
Dadang Suyadi ${ }^{1}$, Aryananda Anugrah Muhamad ${ }^{2}$ \\ Prodi D III Transportasi, Fakultas Teknik - UNJ \\ 2 Prodi D III Transportasi, Fakultas Teknik - UNJ
}

\begin{abstract}
Abstrak. Kegiatan Penelitian Tugas Akhir ini dilakukan selama melakukan kegiatan Praktek Kerja Lapangan di PT. Bhanda Ghara Reksa yang merupakan perusahaan dibidang jasa Express, Warehousing, dan Logistic. Penelitian ini bertujuan untuk mengetahui apa saja prosedur yang dilakukan dan dokumen yang dibutuhkan dalam kegiatan delivery di gudang I, untuk mengetahui juga apakah faktor fasilitas mempengaruhi pengiriman dan kegiatan delivery, serta untuk mengetahui apa saja hambatan yang terjadi dan solusi yang didapat selama melaksanakan kegiatan delivery. Dalam melaksanakan prosedur kegiatan delivery oleh PT. Bhanda Ghara Reksa ada banyak tahapan yang harus dilakukan hingga pada akhirnya barang dikirimkan kepada costumer. Tahapan prosedur yang dimaksud sudah berdasarkan SOP yang berlaku sesuai dengan Peraturan yang ada di PT. Bhanda Ghara Reksa namun masih banyak hambatan-hambatan yang terdapat dalam kegiatan delivery tersebut.
\end{abstract}

Kata kunci :Delivery, fasilitas, pengiriman, hambatan dan solusi.

\section{A. PENDAHULUAN}

Perkembangan logistik di tanah air mengalami kemajuan yang cukup pesat, hal ini terlihat dengan tumbuh suburnya bidang usaha logistik, antara lain yaitu sektor transportasi, pendistribusian, dan warehousing. Seiring dengan perkembangan dunia logistik yang semakin maju perusahaan harus bekerja secara efektif dan efisien untuk dapat meningkatkan mutu dan kualitas pelayan yang lebih baik. Hal ini jelas akan membawa dampak kepada kemampuan perusahaan dalam mengelola bidang usaha yang ada sehingga dapat meningkatkan pangsa pasar yang lebih tinggi di Indonesia.

PT. Bhanda Ghara Reksa salah satu perusahaan pelayanan jasa penyimpanan barang dan transportasi sangat berupaya untuk memberikan kualitas jasanya denga cara meningkatkan mutu pelayanan logistik di Indonesia dengan menyediakan perencanaan dan megoprasikan kegiatan pendistribusian serta layanan jasa penyimpanan secara efektif dan efesien dengan dibantu oleh sumber daya yang terlatih dalam hal pergudangan dan lapangan. Dalam kegiatannya PT. Bhanda Ghara Reksa menyiapkan keperluan yang melibatkan kedua belah pihak antara pengurus barang dan pemilik barang yang dimana barangnya disimpan di gudang PT. Bhanda Ghara Reksa. Kesiapan dokumen seperti proses Reciving, dan Delivery juga menjadi perhatian karena semua proses kegiatan yang ada terintergrasi dengan proses peyimpanan dan pengiriman barang.

Namun, dalam kegiatan atau realitas di lapangan kegiatan Delivery atau saat proses barang akan keluar untuk dikirim kepada costumer terjadi keterlambatan atau ketidaksesuaian terhadap SOP (Standar Operasional Prosedur) yaitu lama proses Delivery yang seharusnya selesai dalam waktu maksimal 60 menit sering terjadi keterlambatan. Faktor sistem SAP (Sistem Aplikasi Prosedur) dan faktor pekerja menjadi faktor terbesar dalam terjadinya hambatan ini.

\section{B. METODE PENELITIAN}

Dalam pembahasan serta beberapa keterangan data yang diperlukkan untuk mengolahnya dalam penulisan karya ilmiah penulis menggunakan data yang dilakukan dengan mengamati secara langsung atas fakta yang terjadi di lapangan PT. Bhanda Ghara Reksa. Untuk mendapatkan data yang akurat, maka dilakukan wawancara terhadap kepala gudang dan karayawan tentang masalah yang ada di kegiatan delivery. Hal ini bertujuan untuk mengetahui lebih detail bagaimana masalah-masalah yang terjadi di kegiatan delivery pada gudang I PT. Bhanda Ghara Reksa, Kelapa Gading, Jakarta Utara. 


\section{Kerangka Berfikir}

Analisa Faktor Fasilitas Menjadi Penyebab Terlambatnya

Pengiriman Dalam Kegiatan

Delivery di Gudang I

PT. Bhanda Ghara Reksa

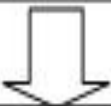

Dari Landasan Teori mempelajari:

1. Pengertian Gudang

2. Pengertian Sistem Fasilitas

3. Pengertian Key Performance Indicator

4. Pengertian Delivery

5. Kegiatan yang terdapat di Gudang I PT. BGR

Meneliti data terkait key performance indikator pada Januari dan Februari 2018

Menganalisa seberapa besar pengaruh fasilitas terhadap kapasitas lapangan out bound, transportasi, dan key performance indicator

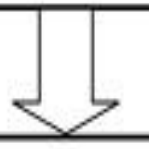

Kesimpulan dan Saran 


\section{PEMBAHASAN}

Pada kegiatan pengerjaan Delivery Note yaitu alur dari picking, scanning sampai dengan loading memiliki masalah terlambatnya waktu pengiriman yang menyebabkan rendahnya KPI (key performance indicator) yang menjadi target serta SOP yang ada di PT. Bhanda Ghara Reksa. Sistem dan prosedur sudang diterapkan di gudang I ini, namun kendala-kendala yang terjadi pada saat pelaksanaan tidak bisa diabaikan begitu saja karna ini menjad penyebab rendahnya KPI (key performance indicator) pada kegiatan delivery note. Berikut ini adalah beberapa kendala yang terjadi berkaitan dengan rendahnya KPI (key performance indicator) pada kegiatan pengerjan delivery note:

a. Sering terjadinya gangguan internet di gudang sehingga proses untuk mengimput barang yang akan keluar menjadi terhambat, target yang seharusnya diselesaikan dalam waktu 1 jam untuk 1 delivery note ini bisa menyebabkan keterlambatan sehingg barang yang keluar lainnya akan menumpuk dilapangan outbound dan tentu saja KPI (key performance indicator) menjadi sangat rendah jauh dibawah target yaitu $85 \%$

b. Kuantitas dalam satu delivery note yang banyak dan berbeda-beda merk, digudang i penempatan barang berdasarka merk-merknya. hal ini berakibat jika terjadi dalam 1 delivery note terdapat banyak merk dapat menyulitkan dan menambah waktu bagi pekerja untuk mengerjakan delivery note tersebut. Tentu saja KPI (key performance indicator) menjadi sangat rendah jauh dibawah target yaitu $85 \%$.

c. Ketidak disiplinan para pekerja yang menyimpan barang di rak penyimpanan tidak sesuai dengan tempat seharusnya, sehingga hal ini mengakibatkan lamanya para pekerja untuk mencari barang yang akan keluar sesuai dengan delivery note yang ada karena alamat rak yang seharusnya tida terdapat pada rak tersebut. Hal ini mengakibatkan lamanya waktu untuk mencari barang tersebut.

d. Delivery note yang banyak sehingga banyak barang yang keluar dihari yang sama meneyebabkan kapasitas didalam gudang melebihi yang seharusnya, sehingga barang harus diletakan di area-area jalan rak penyimpanan yang menyebabkan sulitnya ruang gerak di dalam area gudang. Untuk kuantitas barang yang normal maksimal hanya 240 delivery note dalam sehari dalam SOP yang tertera di PT. Bhanda Ghara Reksa.

\section{E. KESIMPULAN}

Berdasarkan hasil dan analisa dan pembahasan mengenai faktor fasilitas dalam kegiatan delivery di gudang I BGR, maka dapat diambil kesimpulan, yaitu:

1. Tidak seimbangnya barang yang masuk ke gudang dan keluar dari gudang, menyebabkan terjadinya penumpukan di area penyimpanan. Ini terjadi karena tidak menentunya barang yang keluar dari gudang hal itu karena PT. Synex Metrodata indonesia selaku penyewa gudang, hanya mengeluarkan barang yang telah dibeli oleh konsumen sedangkan barang yang masuk setiap hari selalu berdatangan

2. Sasaran atau target yang diterapkan dalam pelaksanaan kegiatan dan lapangan belum mencapai hasil yang maksimal

3. Pekerja yang sering tidak menaati peraturan yang ada dengan menyimpan barang tidak sesuai dengan rak yang seharusnya

\section{F. SARAN}

Saran terhadap analisa dan pembahasan mengenai faktor fasilitas di kegiatan delivery yang menyebabkan terhambatnya pengiriman, yaitu:

1. Manajemen perusahaan harus memastikan penggunaan gudang sesuai SOP dengan melakukan pengawasan rutin dan evaluasi penggunaan tiap bulannya.

2. Pihak perusahaan harus memastikan barang yang keluar dan masuk kedalam gudang harus seimbang tidak terlalu jauh jumlahnya agar tidak terjadi penumpukan.

3. Menambahkan fasilitas yang lengkap dan memadai untuk mempercepat proses kegiatan delivery.

4. Memberika sanksi kepada sumber daya manusia yang menyalahi aturan agar mereka lebih disiplin dalam melaksanan pekerjaan sesuai dengan SOP yang ada di perushaan.

5. Mempercepat proses barang keluar dengan menambah jumlah armada transportasi atau memperbesar ukuran transportasi agar tidak menumpuk di outbound area.

6. Menambah jumlah SDM untuk mempercepat proses barang keluar yang selalu tinggi.

7. Memperhatikan SOP yang ada agar kegiatan berjalan dengan standar yang ada.

8. Memastikan barang yang keluar tidak salah sehingga tidak terjadi pembatalan.

\section{G. DAFTAR PUSTAKA}

1. Suyono, M. Mar, R.P, Capt. 2005. Shipping: Pegertian, Jenis dan Fungsi Gudang

2. Warman, John. 2004 .Manajemen Pergudangan. Jakarta : CV.Mulyasari

3. Bowersox, Donald J. 1978. Manajemen Logistik : Integrasi Sistem-Sistem Manajemen Distribusi Fisik dan Manajemen Material (terjemahan Drs.A.Hasymi Ali). Jakarta : Penerbit Bumi Aksara.

4. Purnomo,Hari. 2004. Perencanaan dan Perancangan Fasilitas. Edisi Pertama, Yogyakarta : Graha Ilmu. 
